\title{
Prevalence and risk factors of acute lower respiratory infection among children living in biomass fuel using households: a community-based cross-sectional study in Northwest Ethiopia
}

\author{
Mesafint Molla Adane ${ }^{1 *}$, Getu Degu Alene², Seid Tiku Mereta ${ }^{3}$ and Kristina L. Wanyonyi ${ }^{4}$
}

\begin{abstract}
Background: Childhood acute lower respiratory infection in the form of pneumonia is recognized as the single largest cause of childhood death globally accounting for $16 \%$ of the overall deaths. Some studies also reported a higher prevalence of childhood acute respiratory infection in Ethiopia, which ranges from 16\% up to 33.5\%. Concerning the risk factors, there are limited community-based studies in Ethiopia in general, and in the current study region in particular. Therefore, the present study was conducted to investigate the prevalence of childhood acute respiratory infection and associated factors in Northwest Ethiopia.
\end{abstract}

Methods: As part of the wider stove trial project, a cross-sectional study was conducted in May 2018 among a total of 5830 children aged less than 4 years old in randomly selected clusters. Binary logistic regression was applied to identify factors linked with childhood acute lower respiratory infection and adjusted odds ratios were used as measures of effect with a 95\% confidence interval.

Results: A total of 5830 children were included in the study within 100 clusters. Out of which $51.7 \%$ were male and 48.3\% female. The prevalence of childhood lower acute respiratory infection was 19.2\% (95\% Cl: 18.2-20.2) and found to decrease among children living in homes with chimney, eaves space and improved cookstove than children living in households with no chimney, eaves space and improved cookstove with estimated AOR of 0.60 (95\% Cl: 0.51-0.70), 0.70 (95\% Cl: 0.60-0.84) and 0.43 (95\% Cl: 0.28-0.67) respectively. It was also associated with other cooking-related factors such as cow dung fuel use [AOR $=1.54(95 \% \mathrm{Cl}: 1.02-2.33)]$, child spending time near stove during cooking $[A O R=1.41$ (95\% Cl: $1.06-1.88)$, presence of extra indoor burning events [AOR $=2.19(95 \% \mathrm{Cl}$ : $1.41-3.40)]$ and with frequent cooking of meals $[A O R=1.55$ (95\% Cl: 1.13-2.13)].

(Continued on next page)

\footnotetext{
* Correspondence: mesafintmolla@yahoo.com

'Department of Environmental Health, School of Public Health, College of Medicine \& Health Sciences, Bahir Dar University, Bahir Dar, Ethiopia

Full list of author information is available at the end of the article
} permission directly from the copyright holder. To view a copy of this licence, visit http://creativecommons.org/licenses/by/4.0/ The Creative Commons Public Domain Dedication waiver (http://creativecommons.org/publicdomain/zero/1.0/) applies to the data made available in this article, unless otherwise stated in a credit line to the data. 
(Continued from previous page)

Conclusion: High prevalence of childhood acute lower respiratory infection was demonstrated by this study and it was found to be associated with household ventilation, cooking technology, and behavioral factors. Therefore, we recommend a transition in household ventilation, cooking technologies as well as in child handling and in the peculiar local extra indoor burning practices.

Keywords: Baking stove, Childhood ARI, Chimney, Cooking fuel, Cookstove, Indoor burning

\section{Background}

Acute respiratory infection (ARI) is the leading cause of morbidity and mortality in low- and middle-income countries (LMICs) [1] across all ages and sexes [2]. Lower respiratory infections caused 652, 572 deaths in children younger than 5 years worldwide in 2016 [3]. Particularly, acute lower respiratory infection (ALRI) in the form of pneumonia is recognized as the single largest cause of childhood death globally accounting for $16 \%$ of the overall deaths in 2015 [4].

In Ethiopia, lower respiratory infections were the leading cause of premature mortality across all ages in the year 2015 [5] and pneumonia, in particular, was the second most common cause of mortality in Northeast Ethiopia [6]. In addition, the 2016 EDHS report confirmed a countrywide ARI prevalence of $7 \%$ among children under 5 years old [7], and a number of cross-sectional studies conducted in different parts of the country reported an even higher prevalence of childhood ARI in Ethiopia which ranges from $16 \%$ up to $33.5 \%$ [8-12].

Concerning the risk factors, studies have shown that household air pollution (HAP) exposure is linked with childhood ALRI $[13,14]$. However, the factors are not identical across different circumstances and further investigations should be extended to other locations, populations, and cultures to determine the relationships more precisely [15]. There are, however, limited community-based studies in Ethiopia in general [16-18], and there is a robust lack of evidence in the current study region in particular as reported by a recent synthesis of situational analysis in Ethiopia [16]. The availability of such evidence would drive commitments by governments, industries, non-governmental organizations, communities, and individual citizens to find suitable HAP prevention methods in order to reduce the burden of preventable HAP related child ARI morbidity and mortality in Ethiopia and somewhere else in LMICs.

Therefore, taking account of the critical need for more evidence in the area as recommended by previous studies [16-18], the present study was conducted to assess the prevalence and factors associated with communityacquired childhood ALRI using the definition of Integrated Management of Childhood Illnesses (IMCI) pneumonia algorithm developed by World Health Organization (WHO) $[19,20]$. The IMCI-pneumonia assessment protocol is a common diagnostic criterion for the classification and treatment of childhood pneumonia at health facilities in Ethiopia [21]. The Ethiopian Demographic and Health Survey (EDHS) [7] and other similar studies conducted in different parts of the world also used this diagnostic criterion for childhood pneumonia assessment; such as the randomized controlled trials conducted in Malawi [22], Rwanda [23], Ghana [24], Indian [25] and Guatemala [26]. In this study, we used the term childhood ALRI as a synonym for the IMCI-pneumonia, because the term childhood ALRI is the preferred expression for childhood pneumonia in peculiar to the developing world countries [27].

\section{Methods \\ Study design}

As part of the wider stove trial project in Northwest Ethiopia (ClinicalTrials.gov Identifier: NCT03612362), a community-based cross-sectional study was employed to determine the prevalence of childhood ALRI \& associated factors among children living in biomass fuel using households in Northwest Ethiopia in which biomass fuel use is a major household energy source for cooking.

\section{Study setting}

This study had been conducted in a low-income rural community of the Mecha Health and Demographic Surveillance System (MHDSS) site in which biomass fuel use is a major household energy source for cooking. MHDSS site is a field research center established in 2013 by Bahir Dar University to conduct and support postgraduate level studies in the region. It is located $525 \mathrm{~km}$ away from the capital city of Ethiopia, Addis Ababa, towards Northwest and $40 \mathrm{~km}$ far away from the capital city of Amhara Regional State, Bahir Dar. The study area comprises three major climatic zones of highlands ("Dega"), Midlands ("Weina Dega"), and lowlands ("Kola"). It also consists of 10 randomly selected Kebeles (sub-districts / the smallest administrative unit) of three urban and 7 rural with a total of 132 clusters/ "Gots". According to the official population profile report of MHDSS, a total of 65, 086 population was registered within 20, 631 households at the end of 2016 . Out of which children $0-4$ years old were accounted for $13.3 \%$ of the total population. 


\section{Study population}

Since this study was part of the wider stove trial project, all households with children aged less than 4 years old with respective mothers/caretakers were recruited in the selected clusters to ensure a minimum of one-year longitudinal data collection before the child's 5th birthday.

\section{Sample size determination}

The sample size of this study was calculated using the population survey formula on EPI INFO program assuming a $95 \%$ confidence level, a 3\% acceptable margin of error, $21 \%$ acceptable estimated population proportion of child ARI in Ethiopia from a previous study [10], a design effect of 2 for cluster sampling, allowing a 5\% addition to account for any unpredictable events and assuming an average number of eligible children within each cluster to be 55 from the updated data of MHDSS, the final estimated sample size was about 1490 eligible children within 27 randomly selected clusters.

However, since we had the advantage of using all the baseline data of the wider stove trial project (ClinicalTrials.gov Identifier: NCT03612362), we considered all the randomly selected 100 clusters containing about 5830 eligible children from the stove trial project in order to attain the advantage of having a larger sample size which would reduce the sampling error thereby increasing the accuracy of estimations. We were also aware of the possible bias that might be introduced, and we did everything possible to deal with it.

\section{Participant sampling technique}

The cluster sampling method was used to select participants using the small villages termed as "Got" in the local language as cluster units. Among the total 132 clusters in the MHDSS site, 100 clusters were selected randomly to represent the total population and all eligible households were included within the selected clusters. The sampling frame, list of households with children aged less than 4 years, was established from the MHDSS record, and the selected households were identified using the permanent MHDSS site house number. Then, the youngest child less than 4 years old was recruited from each household. In situations where there were two or more children aged under-4 years living in the same household, only the youngest child was included in the study.

\section{Variables, data sources, and methods of assessment}

Outcome variable: To classify community-acquired childhood ALRI status (Yes or No), this study used the definition of WHO IMCI-pneumonia [19, 20]. Childhood ALRI was assessed by field nurses through face-toface interviews where mothers/caregivers of the index children were asked about childhood ALRI/Pneumonia signs and symptoms in the preceding 2 weeks. Besides, since nurses trained in IMCI can effectively diagnose ALRI/pneumonia in Ethiopia [21]; physical examination of the ill index child was also conducted by the field nurses using the IMCI pneumonia algorism to overcome some of the limitations of the self-reported health data.

Predictor variables: The predictor variables were categorized into socio-demographic, ventilation, technology, and behavioral as well as other potential predictor variables. These variables were assessed through face-to-face interviews with index child mothers as well as through observations by field workers using questionnaire as mentioned next:

Ventilation: Four features of household ventilation were assessed:

- Chimney was assessed by asking and observing the existence of chimney in the main cooking quarter by classifying into two categories as Yes or No.

- Eaves space was assessed by asking and observing the presence of an open eaves space between the wall and the roof of the main cooking quarter by classifying into two categories as Yes or No.

- The number of windows was assessed through observing the number of windows in the main baking/ cooking area if any.

- Roof leak was assessed through asking and observing the presence of roof leak in the main cooking quarter by classifying into two categories as Yes or No.

Technology: Three aspects of household cooking technology-related factors were considered:

- "Injera" baking stove type was assessed by asking about and observing the primary type of stove used for "Injera" baking purpose and classifying these into two categories i] improved "Injera" baking stove (IBS) ii] traditional baking stove (TBS). The term IBS refers to energy-efficient baking stoves produced by certified manufactures and on sale at commercial markets in Ethiopia and TBS refers to baking stoves constructed by household members for "Injera" baking purpose, which happen to lack energy efficiency and have poor combustion features.

- Cookstove type was assessed by asking and observing the primary cooking stove type by classifying into two categories as improved cookstove or traditional cookstove (TCS). The term ICS refers to a household cooking stove that is designed to use less fuel, save time and reduce the volume of smoke produced compared to the traditional stove and the term traditional cookstove refers to a cookstove constructed by household members for cooking purpose that are not energyefficient and have poor combustion features [12]. 
- Fuel type refers to the source of energy used for household cooking [12, 28], and since all study households primarily use biomass fuel, it was assessed through asking \& observing the primary fuel type used for household cooking purposes by classifying into 3 categories as wood/straw/shrub, cow dung, and charcoal.

Behavioral: The following are the five behavioral factors investigated in this study:

- Child near the stove (child handling practice) was assessed by asking mothers whether their child regularly spent time near stove within $1.5-\mathrm{m}$ distance during cooking times by classifying into two categories as Yes or No.

- Cooking time was assessed through asking respondents what the average time taken for cooking was in hours per day and classifying these into three categories as i] $1-2 \mathrm{~h}$, ii] $3-4 \mathrm{~h}$ and iii] 5 or more hours per day.

- Extra indoor burning event was also assessed. This refers to any extra burning event (such as the burning of incense, coffee ceremony, local alcohol/ "areqi" making or cooking for business) that commonly occurs inside the main cooking quarter other than the customary cooking and may influence the HAP level as alternative sources of HAP. It was assessed by asking and observing the presence of any extra indoor burning occasion inside a household by classifying into two categories (Yes or No).

- Frequency of meal was assessed through asking the number of meals cooked per day by classifying into 4 categories as one or less meal, two, three and four/ more meals

- Window opening practice of the households was assessed by asking the respondent and observing whether the windows were commonly opened in the main cooking quarter.

Other variables: Other variables were also assessed through face-to-face interviews with index child mothers as well as through observations by field workers as mentioned next

- Breast-feeding was assessed by asking mothers whether the child was exclusively breastfed for the first 6 months by classifying into two categories (Yes or No) $[29,30]$.

- Child vaccination refers to the immunization status of the child for his/her respective age by classifying into two categories (Yes/No) \& assessed through asking/card checking
- An outdoor burning event refers to the presence of any extra burning event (such as burning rubbish, charcoal production or local alcohol/“areqi" making that commonly occurs nearby the household and may influence the HAP as an alternative source of HAP exposure. It was assessed by asking \& observing the presence of any outdoor burning event near the household by classifying into two categories (Yes or No).

- Secondary smoking refers to cigarette smoking by a member of the household and it was assessed by asking the presence of any smoking practice at home by classifying into two categories (Yes or No).

\section{Data collection}

Data collection was carried out in May 2018 by trained local nurses through face-to-face interviews with the mothers/caregivers of index children using a pre-tested questionnaire as well as through direct verification (i.e. examination of the ill child) using the IMCI algorithm [19]. The data collection questionnaire (Provided in additional file 1) was developed after a comprehensive literature review and expert evaluation based on the specific objectives of the study. It contains household location, socio-demographic, index child health, main cooking quarter characteristics, cooking pattern and alternative sources of household air pollution related questions of the study households.

To prevent missing data and avoid the associated complexities in data analysis and interpretation, several special efforts were applied before and during the data collection period. To mention some; the stove trial research project was publicized through a live discussion on the Regional Television show in May 2018 to build community interest in the study. Interest in the study was also created through communications about the study during the regular local health development army team meetings as well as through home visits by the local health and agricultural extension workers along with local energy experts by means of working on active community engagement through the Ethiopian health and agricultural extension programs as well as through the local health development army team structure.

Participants were also informed that they will receive an IBS for free either at the initiation or at the end of the study to maintain justice and to help achieve a high level of research participation. Besides, we utilized local household energy experts and health extension workers to oversee the overall efforts in recruiting eligible households. Furthermore, home visits for data collection were scheduled and communicated earlier. Repeated home visits were made to deal with missed data using the permanent MHDSS site house number to identify missed households as well as data collectors training with 
practical exercises on how to avoid non-response were the major efforts to achieve complete participant enrolment.

\section{Data quality assurance}

Prior to the actual data collection, emphasis was given in designing the study tool and training was given for data collectors with a practical exercise on how to collect the required data as well as the study tool was pretested in the nearby district, which was not part of the study area, and the necessary amendments were done on the flow and clarity of some questions to suit respondents. During the actual data collection, data collection manual (Provided in additional file 2) was used by each data collector to facilitate the data collection process and about $5 \%$ of the already surveyed households were randomly selected and reinterviewing took place at the time of data collection as cross-checking mechanism to ensure the validity of the collected data. In addition, all data were checked for completeness, accuracy, and consistency prior to data entry.

\section{Statistical methods}

Since the problem of missing data was avoided by making special efforts a "complete-case" analysis approach was performed using the Statistical Package for Social Sciences. Backward stepwise logistic regression analysis technique was applied to identify factors linked with childhood ALRI by controlling potential confounders simultaneously. All statistical tests were two-sided with $p$-value $<0.05$ considered statistically significant, and an adjusted odds ratio (AOR) with respective confidence interval was used as measures of effect.

Concerning model fitness, once the model has been fitted to the data, the Hosmer \& Lemeshow test was checked and the model is a good fit for the data $(P=$ 0.347) [31]. Besides Hosmer \& Lemeshow test, the goodness-of-fit was also evaluated using a receiver operating characteristic (ROC) curve analysis and the model classifies the group significantly better than by chance with a ROC curve value of 0.735 (95\% CI: 0.719-0.752). In addition, a multicollinearity diagnosis was carried out using the correlation matrix method, and all values were well below 0.20 , which confirmed that multicollinearity among the predictor variables was not a concern for the model.

Furthermore, interaction effect test was performed between some of the independent factors, by adding a term for the product of the two factors to the regression model to assess the interaction effects on the outcome. As a final point, both data analysis and interpretations were made at the child level and the paper is reported following the STROBE (Strengthening the Reporting of Observational Studies in Epidemiology) statement to increase its quality and address the essential components of the report [32].

\section{Results}

Socio-demographic characteristics of study participants

A total of 5830 eligible children were included in the study within 100 clusters. Out of which $51.7 \%$ were male. Most mothers/caretakers were married (92.7\%), do not have formal education (79.1\%) and about two-thirds $(66.8 \%)$ of them were farmers by occupation. About one-third of children (34.7\%) live in households with four up to five family members as shown in Table 1 .

\section{Cooking related characteristics of study households}

The majority of the households use the traditional type of "Injera" baking (94.5\%) and cooking (92.1\%) stoves. All study children live in households that rely principally on high pollution biomass fuels (wood/shrub/straw (80\%), charcoal (14.4\%) and cow dung (5.6\%) for cooking as shown in Table 2. Besides, the presence of extra indoor (95.8\%) and outdoor (38.1\%) burning events such as coffee ceremony, burning incense, local alcohol/ "areqi" making, burning rubbish and charcoal production were common observable facts in the study area as revealed in Table 2.

\section{Prevalence of childhood acute lower respiratory infection} The prevalence of childhood ALRI was 19.2\% (95\% CI: 18.2-20.2). ALRI distribution by gender was found to be $20 \%$ for females and $18.4 \%$ for male children. The distribution by age group was found to be $21.9 \%$ for those aged less than 1 year, $19.7 \%$ for 1 year, $18 \%$ for 2 years and 16\% for 3 years old children as indicated in Table 3.

\section{Factors associated with childhood acute respiratory infection}

The effect of several factors on childhood ALRI status was evaluated by fitting the logistic regression model and a narrative description of the major results is presented next. To start with the findings of sociodemographic factors, the female gender was found to significantly increase the odds of childhood ALRI than the male with an estimated AOR of 1.17 (95\% CI: 1.021.35 ), and the odds of childhood ALRI was found to decrease by $41 \%$ among three-years-old children than under one-year-old children with an estimated AOR of 0.59 (95\% CI: 0.48-0.74). However, children whose mothers' age were between 26 and 35, 36-45, 46-55 and above 56 years old did not show a significant association with the odds of childhood ALRI with AOR of 1.30 ((95\% CI: $1.08-1.57), 1.39$ ((95\% CI: 1.13-1.72), 1.95 ((95\% CI: 1.32-, 2.89) and 2.41 (95\% CI: 1.12-5.18) respectively when compared with children whose mothers' age was between 16 and 25 years old as depicted in Table 4. 
Table 1 Socio-demographic characteristic of study households in Northwest Ethiopia, May 2018

\begin{tabular}{|c|c|c|}
\hline Socio demographic characteristic & Frequency & Percent \\
\hline Response rate & 5830 & 100 \\
\hline \multicolumn{3}{|l|}{ Gender of child } \\
\hline Female & 2816 & 48.3 \\
\hline Male & 3014 & 51.7 \\
\hline \multicolumn{3}{|l|}{ Age of child } \\
\hline$<1$ Year old (0-11 months) & 1601 & 27.5 \\
\hline 1 Year old (12-23 months) & 1664 & 28.5 \\
\hline 2 Years old (24-35 months) & 1528 & 26.2 \\
\hline 3 Years old (36-47 months) & 1037 & 17.8 \\
\hline \multicolumn{3}{|l|}{ Age of mothers/ caretakers } \\
\hline $16-25$ Years & 1318 & 22.6 \\
\hline 26-35 Years & 2854 & 49.0 \\
\hline $36-45$ Years & 1438 & 24.7 \\
\hline $46-55$ Years & 180 & 3.1 \\
\hline$>56$ Years & 40 & 0.6 \\
\hline \multicolumn{3}{|c|}{ Marital status of mothers/ primary caretakers } \\
\hline Married & 5406 & 92.7 \\
\hline Single & 120 & 2.1 \\
\hline Divorced & 232 & 4.0 \\
\hline Separated & 53 & 0.9 \\
\hline Widowed & 19 & 0.3 \\
\hline \multicolumn{3}{|c|}{ Educational status of mothers/ caretakers } \\
\hline Do not have formal education & 4610 & 79.1 \\
\hline Primary school (grade 1-8) & 474 & 8.1 \\
\hline Secondary school (grade 9-12) & 366 & 6.3 \\
\hline Higher education & 380 & 6.5 \\
\hline \multicolumn{3}{|l|}{ Religion of mothers/ caretakers } \\
\hline Orthodox & 5699 & 97.8 \\
\hline Muslim & 123 & 2.1 \\
\hline Protestant & 8 & 0.1 \\
\hline \multicolumn{3}{|c|}{ Occupational status of mothers/ caretakers } \\
\hline Farmer & 3893 & 66.8 \\
\hline Merchant & 839 & 14.4 \\
\hline Housewife & 496 & 8.5 \\
\hline Employee & 332 & 5.7 \\
\hline Daily laborer & 234 & 4 \\
\hline Student & 36 & 0.6 \\
\hline \multicolumn{3}{|l|}{ Total family size of the household } \\
\hline $2-3$ & 1158 & 19.9 \\
\hline $4-5$ & 2025 & 34.7 \\
\hline $6-7$ & 1784 & 30.6 \\
\hline $8-9$ & 746 & 12.8 \\
\hline 10 or more & 117 & 2.0 \\
\hline
\end{tabular}

Table 2 Main cooking quarter characteristics of study households in Northwest Ethiopia, May 2018

\begin{tabular}{|c|c|c|}
\hline Socio demographic characteristic & Frequency & Percent \\
\hline \multicolumn{3}{|l|}{ Location of main cooking quarter } \\
\hline Inside the living house & 2145 & 36.8 \\
\hline Separate kitchen & 3685 & 63.2 \\
\hline \multicolumn{3}{|l|}{ "Injera" baking stove type } \\
\hline Traditional biomass stove & 5508 & 94.5 \\
\hline Improved biomass stove & 322 & 5.5 \\
\hline \multicolumn{3}{|l|}{ Cookstove type } \\
\hline Traditional stove & 5371 & 92.1 \\
\hline Improved stove & 459 & 7.9 \\
\hline \multicolumn{3}{|l|}{ Cooking fuel type } \\
\hline Wood/shrub/straw & 4662 & 80.0 \\
\hline Cow dung & 328 & 5.6 \\
\hline Charcoal & 840 & 14.4 \\
\hline \multicolumn{3}{|l|}{ Type of lamp for household lighting } \\
\hline Electric/Solar & 3760 & 64.5 \\
\hline "Masho"/Candle/ "Fanos" & 1009 & 17.3 \\
\hline "Kuraz" & 979 & 16.8 \\
\hline Wood & 82 & 1.4 \\
\hline \multicolumn{3}{|l|}{ Extra indoor burning event } \\
\hline Yes & 5583 & 95.8 \\
\hline No & 247 & 4.2 \\
\hline \multicolumn{3}{|l|}{ Type of extra indoor burning event } \\
\hline Coffee ceremony \& incense burning & 4166 & 74.6 \\
\hline Local alcohol/"areqi" making & 1417 & 25.4 \\
\hline \multicolumn{3}{|l|}{ Outdoor burning event } \\
\hline Yes & 2224 & 38.1 \\
\hline No & 3606 & 61.9 \\
\hline \multicolumn{3}{|l|}{ Type of outdoor burning event } \\
\hline Burning rubbish & 881 & 15.1 \\
\hline Charcoal production & 549 & 9.4 \\
\hline local alcohol/" areqi" making & 601 & 10.3 \\
\hline Cooking for business & 193 & 3.3 \\
\hline \multicolumn{3}{|l|}{ Secondary smoking } \\
\hline Yes & 104 & 1.8 \\
\hline No & 5726 & 98.2 \\
\hline
\end{tabular}

With reference to household ventilation related factors, the odds of childhood ALRI was found to decrease among children living in a household with a chimney than children living without a chimney with an estimated AOR 0.60 (95\% CI: 0.51-0.70). The odds of childhood ALRI were also found to decrease among children living in a household with an eaves space than children living without an eaves space with estimated AOR of 0.70 (95\% CI: 0.60-0.84). Children living in homes with 
Table 3 Childhood ALRI distribution by gender and age in Northwest Ethiopia, May 2018

\begin{tabular}{|c|c|c|c|c|}
\hline \multirow{2}{*}{$\begin{array}{l}\text { Gender of } \\
\text { child }\end{array}$} & \multirow[t]{2}{*}{ Age } & \multicolumn{2}{|l|}{ ALRI status } & \multirow[t]{2}{*}{ Tota } \\
\hline & & No $(\%)$ & Yes (\%) & \\
\hline \multirow[t]{5}{*}{ Female } & $<1$ Year old (0-11 months) & $622(78.2)$ & $173(21.8)$ & 795 \\
\hline & 1 Year old (12-23 months) & $628(78.9)$ & $168(21.1)$ & 796 \\
\hline & 2 Years old (24-35 months) & $584(80.9)$ & $138(19.1)$ & 722 \\
\hline & 3 Years old (36-47 months) & $418(83.1)$ & $85(16.9)$ & 503 \\
\hline & Sub-total & $2252(80)$ & $564(20)$ & 2816 \\
\hline \multirow[t]{5}{*}{ Male } & $<1$ Year old (0-11 months) & $629(78)$ & $177(22)$ & 806 \\
\hline & 1 Year old (12-23 months) & 708 (81.6) & $160(18.4)$ & 868 \\
\hline & 2 Years old (24-35 months) & $669(83)$ & $137(17)$ & 806 \\
\hline & 3 Years old (36-47 months) & $453(84.8)$ & $81(15.2)$ & 534 \\
\hline & Sub-total & 2459 (81.6) & $555(18.4)$ & 3014 \\
\hline \multirow[t]{5}{*}{ Both genders } & $<1$ Year old (0-11 months) & $1251(78.1)$ & $350(21.9)$ & 1601 \\
\hline & 1 Year old (12-23 months) & $1336(80.3)$ & $328(19.7)$ & 1664 \\
\hline & 2 Years old (24-35 months) & $1253(82)$ & $275(18)$ & 1528 \\
\hline & 3 Years old (36-47 months) & $871(84)$ & $166(16)$ & 1037 \\
\hline & Total & $4711(80.8)$ & $1119(19.2)$ & 5830 \\
\hline
\end{tabular}

four/more rooms were found to decrease the odds of childhood ALRI with an estimated AOR of 0.38 (95\% CI: 0.22-0.65) when compared with children living in one room homes as shown in Table 4.

Concerning household cooking technology-related factors, the odds of childhood ALRI was not showed a significant association with type of "Injera" baking stove, children living in homes with IBS when compared with children living in homes with TBS type with estimated AOR of 0.78 (95\% CI: 0.52-1.15). It showed, however, a significant association with type of cookstove and the odds of childhood ALRI was found to decrease by $57 \%$ among children living in homes with an ICS when compared with children living in homes with traditional cookstove $[\mathrm{AOR}=0.43$ (95\% CI: 0.28-0.67)]. Besides the cookstove technology type, the odds of childhood ALRI showed a significant association with the type of fuel. Children living in cow dung using households as primary cooking fuel type were found to increase the odds of childhood ALRI with an estimated AOR of 1.54 (95\% CI: 1.02-2.33) than children living in charcoal using homes as revealed in Table 4 .

Concerning the findings of behavioral factors, children who were reported to spend some time near stove during cooking were found to increase the odds of childhood ALRI than children who do not spend time near the cookstove with AOR of 1.41 (95\% CI: 1.06-1.88). Similarly, presence of extra indoor burning events such as coffee ceremony, burning incense and production of local alcohol/"Areqi" in the household was associated with more than two-fold increase in the odds of suffering from childhood ALRI with an estimated AOR of
2.19 (95\% CI:1.41-3.40) when compared with no extra indoor burning event in the household. Besides the indoor burning event, presence of outdoor burning events such as charcoal and local alcohol/" areqi" production near the household was found to increase the odds of childhood ALRI with an estimated AOR of 1.69 (95\% CI: 1.06-2.70) when compared with no outdoor burning event. Concerning frequency of meals cooked per day, children living in homes who commonly cooked three and four/more meals per day were found to increase the odds of childhood ALRI than children living in households who cooked one or less meal per day with AOR of 1.46 (95\% CI: 1.14-1.87) and 1.55 (95\% CI: 1.13-2.13) respectively. The odds of childhood ALRI was found to decrease among children who were exclusively breastfed for the first 6 months of life than children who were not breast-fed with an estimated AOR of 0.66 (95\% CI: $0.57-0.77$ ). In the present study, the odds of suffering from childhood ALRI were also elevated by more than twice for secondary smoking with AOR of 2.11 (95\% CI: 1.32-3.36) as presented in Table 4.

Finally, a variety of interaction terms were created and tested between some of the independent factors. Nevertheless, our models did not significantly capture any interaction effect between the cooking-related factors such as "Injera" baking stove type and indoor burning event as well as between cookstove type and average cooking time per day.

\section{Discussion}

This study investigated the occurrence of communityacquired childhood ALRI and associated factors as part 
Table 4 Multivariable analysis of factors associated with childhood ALRI in Northwest Ethiopia, May 2018

\begin{tabular}{|c|c|c|c|c|}
\hline \multirow[t]{2}{*}{ Characteristics } & \multicolumn{2}{|c|}{ ALRI status } & \multirow{2}{*}{$\begin{array}{l}\text { Crude OR } \\
(95 \% \mathrm{Cl})\end{array}$} & \multirow{2}{*}{$\begin{array}{l}\text { AOR } \\
(95 \% \mathrm{Cl})\end{array}$} \\
\hline & No & Yes & & \\
\hline \multicolumn{5}{|l|}{ Gender of child } \\
\hline Female & 2252 & 564 & $1.11(0.97,1.26)$ & $1.17(1.02,1.35)$ \\
\hline Male $^{a}$ & 2459 & 555 & 1.0 & 1.0 \\
\hline \multicolumn{5}{|l|}{ Age of child } \\
\hline$<1$ Year old $^{a}$ & 1251 & 350 & 1.0 & 1.0 \\
\hline 1 Year old & 1336 & 328 & $0.88(0.74,1.04)$ & $0.78(0.65,0.94)$ \\
\hline 2 Years old & 1253 & 275 & $0.78(0.66,0.94)$ & $0.63(0.52,0.77)$ \\
\hline 3 Years old & 871 & 166 & $0.68(0.56,0.84)$ & $0.59(0.48,0.74)$ \\
\hline
\end{tabular}

Age of mother/ caregiver

$\begin{array}{lllll}16-25 \text { Years }^{\mathrm{a}} & 1106 & 212 & 1.0 & 1.0 \\ 26-35 \text { Years }^{-45} & 2304 & 550 & 1.25(1.05,1.48) & 1.30(1.08,1.57) \\ 36-45 \text { Years } & 1141 & 297 & 1.36(1.12,1.65) & 1.39(1.13,1.72) \\ 46-55 \text { Years } & 131 & 49 & 1.95(1.36,2.80) & 1.95(1.32,2.89) \\ >56 \text { Years } & 29 & 11 & 1.98(0.97,4.02) & 2.41(1.12,5.18)\end{array}$

Child vaccination

$\begin{array}{lllll}\text { Yes } & 3605 & 742 & 0.60(0.52,0.70) & 0.60(0.51,0.70) \\ \text { No }^{\mathrm{a}} & 1106 & 377 & 1.0 & 1.0\end{array}$

Breast-feeding

$\begin{array}{llllll}\text { Exclusive } & 3191 & 627 & 0.61(0.53,0.69) & 0.66(0.57,0.77) \\ \text { No or partial }^{\mathrm{a}} & 1520 & 492 & 1.0 & 1.0 \\ \begin{array}{l}\text { Family ALRI history } \\ \text { Yes }\end{array} & & & & \\ \text { No }^{\mathrm{a}} & 988 & 317 & 1.49(1.29,1.73) & 1.36(1.15,1.59) \\ & 3723 & 802 & 1.0 & 1.0\end{array}$

Number of rooms in living house

$\begin{array}{lllll}1 \text { room }^{\mathrm{a}} & 1050 & 334 & 1.0 & 1.0 \\ 2 \text { rooms } & 2608 & 595 & 0.72(0.62,0.84) & 0.45(0.37,0.54) \\ 3 \text { rooms } & 930 & 171 & 0.58(0.47,0.71) & 0.45(0.35,0.57) \\ 4 \text { or more rooms } & 123 & 19 & 0.49(0.30,0.80) & 0.38(0.22,0.65)\end{array}$

Location of cooking quarter

$\begin{array}{lllll}\text { Inside living house } & 1632 & 513 & 1.60(1.40,1.82) & 1.36(1.16,1.59) \\ \text { Separate kitchen }^{\mathrm{a}} & 3079 & 606 & 1.0 & 1.0\end{array}$

Chimney

$\begin{array}{llllll}\text { Yes } & 2043 \quad 340 & 0.57 & (0.50,0.66) & 0.60 & (0.51,0.70)\end{array}$

$\begin{array}{lllll}\mathrm{No}^{\mathrm{a}} & 2668 & 779 & 1.0 & 1.0\end{array}$

Eaves space

$\begin{array}{lllll}\text { Yes } & 2442 & 460 & 0.65(0.57,0.74) & 0.70(0.60,0.84) \\ \mathrm{No}^{\mathrm{a}} & 2269 & 659 & 1.0 & 1.0\end{array}$

"Injera" baking stove type

$\begin{array}{lllll}\text { Traditional }^{\mathrm{a}} & 4425 & 1083 & 1.0 & 1.0 \\ \text { IBS } & 286 & 36 & 0.51(0.36,0.73) & 0.78(0.52,1.15)\end{array}$

Frequency of "Injera" baking event

1.0

1.0
Table 4 Multivariable analysis of factors associated with childhood ALRI in Northwest Ethiopia, May 2018 (Continued)

\begin{tabular}{|c|c|c|c|c|}
\hline \multirow[t]{2}{*}{ Characteristics } & \multicolumn{2}{|c|}{ ALRI status } & \multirow{2}{*}{$\begin{array}{l}\text { Crude OR } \\
(95 \% \mathrm{Cl})\end{array}$} & \multirow{2}{*}{$\begin{array}{l}\text { AOR } \\
(95 \% \mathrm{Cl})\end{array}$} \\
\hline & $\overline{\mathrm{No}}$ & Yes & & \\
\hline Every other day & 501 & 120 & $0.70(0.55,0.90)$ & $0.74(0.56,0.98)$ \\
\hline Every 3 days & 3428 & 753 & $0.64(0.54,0.76)$ & $0.66(0.55,0.81)$ \\
\hline Every 4 or more days & 126 & 22 & $0.51(0.32,0.82)$ & $0.60(0.36,1.00)$ \\
\hline \multicolumn{5}{|l|}{ Cookstove type } \\
\hline Traditional $^{a}$ & 4304 & 1067 & 1.0 & 1.0 \\
\hline Improved & 407 & 52 & $0.52(0.38,0.69)$ & $0.43(0.28,0.67)$ \\
\hline \multicolumn{5}{|l|}{ Cooking fuel type } \\
\hline Cow dung & 225 & 103 & $2.80(2.07,3.80)$ & $1.54(1.02,2.33)$ \\
\hline Wood/ straw/ shrub & 3764 & 898 & $1.46(1.19,1.80)$ & $1.10(0.79,1.53)$ \\
\hline Charcoal $^{a}$ & 722 & 118 & 1.0 & 1.0 \\
\hline
\end{tabular}

Frequency of meal cooked per day

\begin{tabular}{|c|c|c|c|c|}
\hline One or less ${ }^{a}$ & 914 & 176 & 1.0 & 1.0 \\
\hline Two & 2764 & 602 & $1.13(0.94,1.36)$ & $1.22(0.99,1.51)$ \\
\hline Three & 758 & 250 & $1.71(1.38,2.13)$ & $1.46(1.14,1.87)$ \\
\hline Four/more & 275 & 91 & $1.72(1.29,2.29)$ & $1.55(1.13,2.13)$ \\
\hline \multicolumn{5}{|l|}{ Cooking time per day } \\
\hline $1-2 h^{a}$ & 1299 & 218 & 1.0 & 1.0 \\
\hline $3-4 h$ & 2905 & 717 & $1.47(1.25,1.74)$ & $1.54(1.28,1.86)$ \\
\hline 5 or more hours & 507 & 184 & $2.16(1.73,2.70)$ & $1.75(1.37,2.24)$ \\
\hline
\end{tabular}

Child near stove

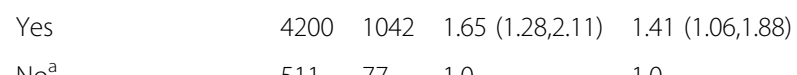

$\begin{array}{llll}511 & 77 & 1.0 & 1.0\end{array}$

Secondary smoking

$\begin{array}{lllll}\text { Yes } & 71 & 33 & 1.99(1.31,3.02) & 2.11(1.32,3.36) \\ \mathrm{No}^{\mathrm{a}} & 4640 & 1086 & 1.0 & 1.0\end{array}$

Extra indoor burning event

$\begin{array}{lllll}\text { Yes } & 4492 & 1091 & 1.90(1.28,2.83) & 2.19(1.41,3.40) \\ \mathrm{No}^{\mathrm{a}} & 219 & 28 & 1.0 & 1.0\end{array}$

Outdoor burning event

\begin{tabular}{lllll} 
Yes & 1651 & 573 & $1.95(1.71,2.22)$ & $1.69(1.06,2.70)$ \\
No $^{\mathrm{a}}$ & 3060 & 546 & 1.0 & 1.0 \\
\hline
\end{tabular}

${ }^{a}$ reference category

of the ongoing trial project on the impact of improved "Injera" baking stove use on childhood ALRI prevention in Northwest Ethiopia. The entire study households used high pollution biomass fuels as the primary household energy source in the form of wood/shrub/straw (80\%), charcoal (14.4\%) and cow dung (5.6\%). This finding is similar with previous studies conducted in rural households of Ethiopia which reported 99.9\% [28], 100\% [10] and 95\% [33] biomass fuel use. In addition, a recent study has also reported that only $12.6 \%$ of the households used clean fuel energy sources in Southern Ethiopia [34]. Correspondingly, a study in Ghana also 
indicated that $99 \%$ of the households use biomass as their primary fuel source [35] and according to the global solid-fuel use estimation, 2.8 billion people still burn solid fuels for cooking [36]. However, HAP exposure from cooking with biomass fuels has been linked with childhood pneumonia [37, 38] and an up to date estimate of the disease burden of HAP suggests that every year, HAP from biomass fuel use causes 455,000 ALRI deaths and an ALRI population attributable fraction of $52 \%$ globally [39]. The use of unclean fuel for household cooking was also found to elevate the odds of childhood ARI in South Ethiopia with an AOR of 2.09 (95\% CI: 1.03-4.22) [34]. Furthermore, excess biomass fuel harvesting has been also linked with environmental implications through deforestation and soil productivity in North Ethiopia [40].

Therefore, given cooking with biomass fuels has been linked with childhood ALRI and environmental pollution, this complete reliance on biomass fuels might expose children to a high risk of ALRI in the study area, and the use of cleaner fuels could be the most important intervention to reduce ALRI among children, who are often most at risk for HAP exposure in particular [41]. The finding of this study has important implications for public health and environmental programs and can be used to formulate public health and environmental policies towards addressing childhood ALRI morbidity and mortality from HAP exposures as well as mitigating climate change.

Concerning the prevalence of childhood ALRI, the result of this study demonstrates a higher prevalence of childhood ALRI (19.2\%; 95\% CI: 18.2-20.2). This finding is somewhat in agreement with two previous studies which reported a prevalence of 21\% [10] and 23.9\% [12] in South and central Ethiopia respectively. However, the finding of this study is found to be contradictory with the finding of other previous cross-sectional studies. On one hand, it is lower than the finding of two studies which reported a prevalence of 33.5\% [8] and 26.3\% [9] in South and Northwest Ethiopia respectively; on the other hand, it is higher than the finding of a study which reported a prevalence of $16.1 \%$ [11] in Northwest Ethiopia. This disagreement might be partly explained by a difference in socio-demographic characteristics, climatic zone, and local cooking characteristics as well as seasonal variation of the studies undertaken. The availability of this finding could drive commitments by stakeholders to identify ALRI as a priority health problem and seek appropriate solutions to reduce its burden particularly among children in Ethiopia and other LMICs.

Regarding the factors associated with childhood ALRI, discussions of the major findings are presented next in four categories as socio-demographic, household ventilation, cooking technology, and behavioral factors. To start with the socio-demographic factors, the female gender was found to significantly increase the odds of childhood ALRI than the male gender with an estimated AOR of 1.17 (95\% CI: 1.02-1.35). Similarly, a previous study conducted in Brazil among under 5 years old children reported that male gender constituted a protective factor against child pneumonia with an estimated AOR of 0.53 [42]. The function of sex in the incidence of childhood community-acquired pneumonia remains unclear [43, 44] and more research is needed for a better explanation of this gender disparity in the risk of childhood ALRI.

Concerning household ventilation related variables; the finding suggests that children living in a household with a chimney were found to decrease the odds of childhood ALRI by $40 \%$ than children living without a chimney with estimated AOR of 0.60 (95\% CI: $0.51-$ $0.70)$. The reason for this result could be a difference in HAP exposure caused by difference in stove venting using a chimney for removing indoor contaminants and it was fairly in concurrence with a study conducted in Southern part of Ethiopia which report the absence of chimney as a risk factor for childhood ARI $(P<0.05)$ [10]. Similarly, previous randomized controlled trial also reported a $22 \%$ reduction in childhood pneumonia from chimney stove intervention in Guatemala [26]. Hence, this considerable link between the use of chimney and childhood pneumonia risk reduction suggests the need for chimney intervention to reduce childhood pneumonia in the study area.

Concerning household cooking technologies, the odds of childhood ALRI did not show a significant association among children living in households with IBS when compared with children living in households with TBS type with an estimated AOR of 0.78 (95\% CI: 0.52-1.15). The possible rationalization for this finding might be the currently distributed biomass-fuelled IBS technologies in Ethiopia may not be improved enough to reduce the odds of childhood ALRI when compared with the biomass-fuelled TBS type. The relationship needs to be further investigated using a more rigorous design with direct measures of HAP exposure and childhood ALRI outcome. Such research is important because large-scale initiatives for the dissemination of IBSs are still underway in Ethiopia [45, 46], and perhaps, no communitylevel biomass IBS trial research had been conducted [16-18] and health effect of the fuel-efficient IBS [46] is unknown.

Concerning cookstove technology, the odds of childhood ALRI was found to decrease by $57 \%$ among children living in homes with an ICS technology when compared with children living in homes with traditional cookstove $[\mathrm{AOR}=0.43$ (95\% CI: $0.28-0.67)$ ]. This finding was somewhat in line with a study conducted in slum households of Addis Ababa in Ethiopia, which 
showed children living in traditional stove using homes were found 6 times more likely to suffer from ALRI than that of the improved stove using homes with AOR of 6.07 (95\% CI: 1.62-22.76) [12]. Likewise, a recent stove trial reported that an improved cookstove (ICS) intervention was not able to reduce the risk of pneumonia among young children in rural Malawi with an incidence rate ratio of 1.01 [22]. In contrast to our finding, a randomized controlled trial reported a significant association of childhood pneumonia reduction (RR 0.82; 0.70, 0.98) among the intervention group [26]. This difference in the effectiveness of ICSs might be explained by a difference in the ethnic group, geographical location, local fuel resources and seasonal variations of the studies undertaken [47].

The other finding worth highlighting is related to fuel type, the odds of childhood ALRI was also found significantly linked with primary household cooking fuel type. Children living in cow dung fuel using homes were found to increase the odds of childhood ALRI than children living in charcoal using homes $[\mathrm{AOR}=1.54(95 \%$ CI: 1.02-2.33)]. The potential explanation for this finding might be different household fuel types result in different toxicities, with HAP from animal dung being extremely toxic $[48,49]$. Hence, the use of cleaner stoves and fuels would be the most important cooking technology related intervention to reduce ALRI among children, and this finding can have important implications for public health programs and provides the evidence needed by policy-makers regarding the benefits of ICS and clean fuel technology adoptions on prevention of childhood ALRI.

Pertaining to the findings of behavioral factors, children who were reported to spend some time near cookstove during cooking were found to raise the odds of childhood ALRI than children who did not spend time near the cookstove with AOR of 1.41 (95\% CI: 1.061.88). The possible explanation for the difference in childhood ALRI risk might be the reflection of the difference in HAP exposure caused by differences in distance from source and length of exposure time. Likewise, a significant association of childhood ALRI was reported with the carrying of a child while cooking with AOR of 1.66 (95\% CI: 1.18-2.34) in South Ethiopia [34]. This finding implies that the practice of keeping children near cooking areas, carried on the back or placed near their mother to sleep, is a common practice in Ethiopia, and they became more at risk of ALRI associated with more proximal exposure of $\operatorname{HAP}[12,34]$. Hence, modifying child handling practices might be effective to decrease the risk of childhood ALRI from proximal exposure of HAP.

The other noteworthy behavioral finding was the effect of extra indoor burning events. Presence of extra indoor burning events, such as coffee ceremony, burning incense and local alcohol/" areqi" making in the household, was associated with more than two-fold increase in the odds of suffering from childhood ALRI with an estimated AOR of 2.19 (95\% CI:1.41-3.40) when compared with no extra indoor burning event. This might be due to an increase in indoor particulate matter concentration as stated by a pilot study conducted among coffee ceremony participants in Addis Ababa homes which reported that the Ethiopian coffee ceremony inside houses could increase the concentration of HAP [50]. The most important inference of this finding is that HAP exposure from extra indoor burning events such as coffee ceremony, burning incense and local alcohol/"areqi" making in the household might elevate the odds of suffering from ALRI in children and this should be further investigated to estimate the separate childhood risks and recommend possible interventions.

The other finding worth highlighting is related to the frequency of meals cooked per day, children living in households who commonly cooked three and four/more meals per day were found to increase the odds of childhood ALRI with AOR of 1.46 (95\% CI: 1.14-1.87) and 1.55 (95\% CI: 1.13-2.13) respectively than children living in households who cooked one or less meal per day. This might be due to high HAP from frequent cooking events which are thought to be a predictor of HAP as reported by a large sample size longitudinal study conducted in rural Ethiopia [51]. In the typical context, this frequent cooking practice might determine both HAP exposure and resulting ALRI risk among under 4 years old children due to several periods of intense cooking smoke exposure per day as evidenced by previous studies conducted in Ethiopia [12, 34]. Hence, modifying child handling practices might be effective to decrease the risk of childhood ALRI from frequent exposure of HAP per day.

In the present study, breastfeeding for the first 6 months was found to decrease the odds of childhood ALRI by about 34\% with an estimated AOR of 0.66 (95\% CI: $0.57-$ 0.77). This finding was in agreement with a case-control study in Southwest Ethiopia which reported that nonexclusive breastfeeding during the first 6 months of life increases the odds of childhood pneumonia by more than three-fold [29]. This might be explained by the protective effect of exclusive breastfeeding on incidence of childhood pneumonia as evidenced by previous studies $[30,52]$.

The odds of suffering from childhood ALRI was elevated by more than twice for secondary smoking with AOR of 2.11 (95\% CI: 1.32-3.36) in the present study. In the same line, a facility-based study carried out in Southwest Ethiopia reported nearly a two-fold increase in community-acquired pneumonia among 2-59 months old children associated with current parental cigarette 
smoking with OR of 1.9 (95\% CI: 1.1-3.7) [29]. In addition, a previous study also showed that second-hand smoke exposure, particularly from household tobacco smoke, increases the risk of lower respiratory tract infections in children [53], and that indoor smoking cessation might be effective to decrease the risk of childhood ALRI.

Concerning interaction effects between cookingrelated factors, a variety of interaction terms were created and tested between some of the independent factors, by adding a term for the product of the two factors to the regression model. Nevertheless, our models did not significantly capture any interaction effect between the cooking-related factors such as "Injera" baking stove type and indoor burning event as well as between cookstove type and average cooking time per day. This finding might be explained by the fact that interaction effect might not always be noted, or it might not be captured adequately by our models due to the complex nature of the interaction effects $\mathrm{s}$ between factors [54], and this should be investigated further in future childhood ALRI risk studies for a better estimation of the relationship between household cooking-related factors and childhood ALRI outcome.

\section{Generalisability}

Concerning the generalisability (external validity) of results, this study aimed to estimate the prevalence and factors associated with community-acquired childhood ALRI using the standard definition of Integrated Management of Childhood Illnesses (IMCI) algorithm. Besides, our study sample size was large and similar to the wider population of biomass fuel using households in the study area, which is representative of the biomass fuel user communities in Ethiopia. Moreover, the pragmatic approach that we used could ensure the generalisability of the study findings to the wider population by maintaining the external validity of results. Hence, the findings of this study could be generalized to biomass fuel user communities in Ethiopia and other LMICs.

\section{Strength and limitation}

Our study has several strengths such as; it was community-based with a large sample size, application of data collection manual and cross-checking mechanisms were among others. This study is also subject to the limitations of survey questionnaires, including recall bias, and the point prevalence estimate which might be influenced by the season during which the survey took place. Besides, although the definition used for this study is intended to quantify childhood ALRI using the standard childhood pneumonia algorism [19, 20], childhood acute upper respiratory illness may have been included in the reported prevalence.

\section{Conclusion}

High prevalence of childhood ALRI was demonstrated by this study which was associated with factors such as household ventilation (chimney \& eaves space), cooking technologies (stove and fuel type) and household behavior (child handling and extra indoor cooking events). The findings of this large-sample study are generally consistent with the results obtained from previous studies. Thus, stakeholders shall work further to reduce childhood ALRI from HAP exposure through enhancing ventilation, making the transition to clean cooking technology as well as through behavioral changes in child handling and cooking patterns. In addition, considering interaction effects in future childhood ALRI risk studies is recommended for a better understanding and estimation of the relationship between household cookingrelated factors and childhood ALRI. Conducting further study is also imperative to better understand how HAP reduction interventions are effective to reduce the health risks among the most susceptible segment of the population such as children.

\section{Supplementary information}

Supplementary information accompanies this paper at https://doi.org/10. 1186/s12889-020-08515-w.

Additional file 1. Data collection questionnaire (English-version).

Additional file 2. Data collectors' manual (English-version).

\section{Abbreviations \\ ALRI: Acute lower respiratory infection; AOR: Adjusted odds ratio; EDHS: Ethiopian Demographic and Health Survey; HAP: Household air pollution; IBS: Improved baking stove; ICS: Improved cookstove; IMCI: Integrated Management of Childhood Illnesses; LMICs: Low-and middle-income countries; MHDSS: Mecha Health and Demographic Surveillance System; SPSS: Statistical Package for Social Science; TBS: Traditional baking stove; TCS: Traditional cookstove; WHO: World Health Organization}

\section{Acknowledgments}

We would like to thank the School of Public Health, College of Medicine and Health Sciences, Research and Community Service Vice President at Bahir Dar University for having funded this overlooked research topic through the funding scheme of MHDSS at Bahir Dar University in Ethiopia. In addition, we would like to thank all colleagues at the School of Public Health, College of Medicine and Health Sciences, Bahir Dar University for their contribution in reviewing and providing comments. We would like to extend our gratitude to health extension workers, field data collectors, supervisors as well as mothers/caretakers of study children who participated in this study. To end with, We would like to express our gratitude to Amhara Regional State Health Bureau, West Gojjam Zonal Health Department and "Mecha" District Health Office.

\section{Authors' contributions}

MMA was the principal investigator of the study and took the leading responsibility starting from origin, design and supervising data collection process to the final analysis and preparation of the manuscript. GDA and STM contribute in supervising the study, reviewing the document and providing critical comments from the design and data collection process to the final analysis and preparation of the manuscript. KLW contributes in reviewing the document and providing critical comments from the design 
and final analysis to the preparation of the manuscript. All authors read and approved the final manuscript.

\section{Funding}

This work was supported by Bahir Dar University through the research funding system of MHDSS [grant number RCS/253/09]. The funder played no role in the conception, methodology, and interpretation of data or reporting of this study.

\section{Availability of data and materials}

The data that support the findings of this study are available from the corresponding author on reasonable request and with permission of the MHDSS research center at Bahir Dar University in Ethiopia.

\section{Ethics approval and consent to participate}

Proposal for the study was reviewed and obtained approval on April 04/2018 from the Ethical Review Committee of College Medicine and Health Sciences at Bahir Dar University (protocol number: 088/18-04). Written informed consent was obtained from every parent or guardian for children to participate in the study following the distribution of written information sheets in "Amharic" (both official \& study area language) to all parents or guardians. The informed consent process emphasized voluntary participation and consent to participation could be withdrawn at any time, without giving a reason and without affecting their current or future benefits to which the participant was entitled. III children were referred to the nearest health institution for appropriate treatment. In addition, no investigation was performed beyond the approved proposal and all data were analyzed anonymously.

\section{Consent for publication}

Not Applicable.

\section{Competing interests}

The authors declare that they have no competing interests.

\section{Author details}

${ }^{1}$ Department of Environmental Health, School of Public Health, College of Medicine \& Health Sciences, Bahir Dar University, Bahir Dar, Ethiopia. ${ }^{2}$ Department of Epidemiology and Biostatistics, School of Public Health, College of Medicine \& Health Sciences, Bahir Dar University, Bahir Dar, Ethiopia. ${ }^{3}$ Departments of Environmental Health Science and Technology, Jimma University, Jimma, Ethiopia. ${ }^{4}$ Department of Dental Academy, Faculty of Science, University of Portsmouth, Portsmouth, England.

Received: 4 December 2019 Accepted: 12 March 2020

Published online: 19 March 2020

\section{References}

1. Walker CL, Rudan I, Liu L, Nair H, Theodoratou E, Bhutta ZA, et al. Global burden of childhood pneumonia and diarrhoea. Lancet. 2013;381(9875): 1405-16 PubMed PMID: 23582727.

2. Kassebaum N, Kyu HH, Zoeckler L, Olsen HE, Thomas K, Pinho C, et al. Child and adolescent health from 1990 to 2015: findings from the global burden of diseases, injuries, and risk factors 2015 study. JAMA Pediatr. 2017;171(6): 573-92.

3. Troeger C, Forouzanfar M, Rao PC, Khalil I, Brown A, Swartz S, et al. Estimates of the global, regional, and national morbidity, mortality, and aetiologies of lower respiratory tract infections in 195 countries: a systematic analysis for the global burden of disease study 2015. Lancet Infect Dis. 2017;17(11):1133-61.

4. Cilloniz C, Martin-Loeches I, Garcia-Vidal C, San Jose A, Torres A. Microbial etiology of pneumonia: epidemiology, diagnosis and resistance patterns. Int J Mol Sci. 2016;17(12):2120.

5. Misganaw A, Haregu TN, Deribe K, Tessema GA, Deribew A, Melaku YA, et al. National mortality burden due to communicable, non-communicable, and other diseases in Ethiopia, 1990-2015: findings from the global burden of disease study 2015. Popul Health Metrics. 2017;15(1):29.

6. Abejew AA, Tamir AS, Kerie MW. Retrospective analysis of mortalities in a tertiary care hospital in Northeast Ethiopia. BMC Res Notes. 2014;7(1):46.

7. Central Statistical Agency (CSA) [Ethiopia] and ICF. Ethiopia demographic and health survey 2016. Addis Ababa and Rockville: CSA and ICF; 2016.
8. Abuka T. Prevalence of pneumonia and factors associated among children 2-59 months old in Wondo genet district, Sidama zone, SNNPR, Ethiopia. Current pediatric research; 2017.

9. Alemayehu M, Alemu K, Sharma HR, Gizaw Z, Shibru A. Household fuel use and acute respiratory infections in children under five years of age in Gondar city of Ethiopia. J Environ Earth Sci. 2014;4(7):77-85.

10. Desalegn B, Suleiman $H$, Asfaw A. Household fuel use and acute respiratory infections among younger children: an exposure assessment in Shebedino Wereda, southern Ethiopia. Afr J Health Sci. 2011;18(1-2):31-6.

11. Fekadu GA, Terefe MW, Alemie GA. Prevalence of pneumonia among underfive children in Este town and the surrounding rural Kebeles, Northwest Ethiopia: a community based cross sectional study. Science. 2014;2(3):150-5.

12. Sanbata $H$, Asfaw A, Kumie A. Association of biomass fuel use with acute respiratory infections among under-five children in a slum urban of Addis Ababa, Ethiopia. BMC Public Health. 2014;14(1):1122.

13. Bruce N, Smith KR, Balmes J, Pope D, Dherani M, Zhang J. Review 4: health effects of household air pollution (HAP) exposure. Geneva: World Health Organization; 2014.

14. MacIntyre EA, Gascon Merlos M, Sunyer Deu J, Cirach M, Nieuwenhuijsen MJ, Heinrich J. Air pollution and respiratory infections during early childhood: an analysis of 10 European birth cohorts within the ESCAPE project. Environ Health Perspect. 2014;122(1):107-13.

15. Martin WJ 2nd, Glass Rl, Araj H, Balbus J, Collins FS, Curtis S, et al. Household air pollution in low- and middle-income countries: health risks and research priorities. PLoS Med. 2013;10(6):e1001455 PubMed PMID: 23750119. Pubmed Central PMCID: 3672215.

16. Berhane K, Kumie A, Samet J. Health effects of environmental exposures, occupational hazards and climate change in Ethiopia: synthesis of situational analysis, needs assessment and the way forward. Ethiop J Health Dev. 2016;30(1):50-6.

17. Kumie A, Samet J, Berhane K. Air pollution, occupational health and safety, and climate change: findings, research needs and policy implications establishing a GEOHealth hub for East Africa. Situational analysis and needs assessment for Ethiopia. 2014.

18. Tefera W, Asfaw A, Gilliland F, Worku A, Wondimagegn M, Kumie A, et al. Indoor and outdoor air pollution-related health problem in Ethiopia: review of related literature. Ethiop J Health Dev. 2016;30(1):5-16.

19. World Health Organization, Handbook IMCl: integrated management of childhood illness. 2005.

20. World Health Organization. Revised WHO classification and treatment of pneumonia in children at health facilities: quick reference guide. Geneva: World Health Organization, 2014.

21. Federal Democratic Republic of Ethiopia Ministry of Health integrated management of newborn and childhood illness, Part 1. Series on the internet. Available at: https://www.open.edu/openlearncreate/pluginfile.php/ 71990/mod_resource/content/2/IMNCI_Part_1_Final_Print-ready_March_2 011_.pdf. Accessed 15 Dec 2017.

22. Mortimer K, Ndamala CB, Naunje AW, Malava J, Katundu C, Weston W, et al. A cleaner burning biomass-fuelled cookstove intervention to prevent pneumonia in children under 5 years old in rural Malawi (the cooking and pneumonia study): a cluster randomised controlled trial. Lancet. 2017; 389(10065):167-75.

23. Nagel CL, Kirby MA, Zambrano LD, Rosa G, Barstow CK, Thomas EA, et al. Study design of a cluster-randomized controlled trial to evaluate a largescale distribution of cook stoves and water filters in Western Province, Rwanda. Contemp Clin Trials Commun. 2016;4:124-35.

24. Jack DW, Asante KP, Wylie BJ, Chillrud SN, Whyatt RM, Quinn AK, et al. Ghana randomized air pollution and health study (GRAPHS): study protocol for a randomized controlled trial. Trials. 2015;16(1):420.

25. Krishnan A, Amarchand R, Gupta V, Lafond KE, Suliankatchi RA, Saha S, et al. Epidemiology of acute respiratory infections in children-preliminary results of a cohort in a rural north Indian community. BMC Infect Dis. 2015;15(1):462.

26. Smith KR, McCracken JP, Weber MW, Hubbard A, Jenny A, Thompson LM, et al. Effect of reduction in household air pollution on childhood pneumonia in Guatemala (RESPIRE): a randomised controlled trial. Lancet. 2011;378(9804):1717-26 PubMed PMID: 22078686.

27. Ranganathan SC, Sonnappa S. Pneumonia and other respiratory infections. Pediatr Clin N Am. 2009:56(1):135-56.

28. Kumie A, Emmelin A, Wahlberg S, Berhane Y, Ali A, Mekonnen E, et al. Magnitude of indoor NO2 from biomass fuels in rural settings of Ethiopia. Indoor Air. 2009;19:14-21. 
29. Geleta D, Tessema F, Ewnetu H. Determinants of community acquired pneumonia among children in Kersa District, Southwest Ethiopia: facility based case control study. J Pediatr Neonatal Care. 2016;5(2):00179.

30. Lamberti LM, Zakarija-Grković I, Walker CLF, Theodoratou E, Nair H, Campbell $\mathrm{H}$, et al. Breastfeeding for reducing the risk of pneumonia morbidity and mortality in children under two: a systematic literature review and meta-analysis. BMC Public Health. 2013;13(3):S18.

31. Bewick V, Cheek L, Ball J. Statistics review 14: logistic regression. Crit Care. 2005:9:112-8.

32. Von Elm E, Altman DG, Egger M, Pocock SJ, Gøtzsche PC, Vandenbroucke $J P$, et al. The strengthening the reporting of observational studies in epidemiology (STROBE) statement: guidelines for reporting observational studies. Int J Surg. 2014;12(12):1495-9.

33. Kooser SH. Clean cooking: the value of clean cookstoves in Ethiopia. J Environ Resour Econ Colby. 2014;1(01):9.

34. Admasie A, Kumie A, Worku A. Children under five from houses of unclean fuel sources and poorly ventilated houses have higher odds of suffering from acute respiratory infection in Wolaita-Sodo, southern Ethiopia: a casecontrol study. J Environ Public Health. 2018;2018:9320603.

35. Van Vliet ED, Asante K, Jack DW, Kinney PL, Whyatt RM, Chillrud SN, et al. Personal exposures to fine particulate matter and black carbon in households cooking with biomass fuels in rural Ghana. Environ Res. 2013; 127:40-8.

36. Bonjour S, Adair-Rohani H, Wolf J, Bruce NG, Mehta S, Prüss-Ustün A, et al. Solid fuel use for household cooking: country and regional estimates for 1980-2010. Environ Health Perspect. 2013;121(7):784.

37. Nguyen T, Tran T, Roberts C, Graham S, Marais B. Child pneumonia-focus on the Western Pacific region. Paediatr Respir Rev. 2017;21:102-10.

38. Dherani M, Pope D, Mascarenhas M, Smith KR, Weber M, Bruce N. Indoor air pollution from unprocessed solid fuel use and pneumonia risk in children aged under five years: a systematic review and meta-analysis. Bull World Health Organ. 2008:86(5):390-8C.

39. Smith KR, Bruce N, Balakrishnan K, Adair-Rohani H, Balmes J, Chafe Z, et al. Millions dead: how do we know and what does it mean? Methods used in the comparative risk assessment of household air pollution. Annu Rev Public Health. 2014;35:185-206.

40. Gebreegziabher Z, Van Kooten GC, Van Soest DP. Technological innovation and dispersion: environmental benefits and the adoption of improved biomass cookstoves in Tigrai, northern Ethiopia. Energy Econ. 2017;67:337-45.

41. Qu F, Weschler LB, Sun $Y$, Sundell J. High pneumonia lifetime-ever incidence in Beijing children compared with locations in other countries, and implications for national PCV and Hib vaccination. PLoS One. 2017; 12(2):e0171438.

42. da Fonseca Lima EJ, Mello MJG, Lopes MIL, Serra GHC, Lima DEP, Correia JB. Risk factors for community-acquired pneumonia in children under five years of age in the post-pneumococcal conjugate vaccine era in Brazil: a case control study. BMC Pediatr. 2016;16(1):157.

43. Falagas ME, Mourtzoukou EG, Vardakas KZ. Sex differences in the incidence and severity of respiratory tract infections. Respir Med. 2007;101(9):1845-63.

44. Muenchhoff M, Goulder PJ. Sex differences in pediatric infectious diseases. J Infect Dis. 2014:209(suppl_3):S120-S6.

45. The Federal Democratic Republic of Ethiopia. Ethiopia's climate resilient green economy strategy. 2011

46. Beyene AD, Bluffstone R, Gebreegziabher Z, Martinsson P, Mekonnen A, Vieider F. The improved biomass stove saves wood, but how often do people use it? Evidence from a randomized treatment trial in Ethiopia: the World Bank; 2015

47. Mohammadreza S, Hesamoddin S. A comprehensive review of technical aspects of biomass cookstoves. Renew Sust Energ Rev. 2017;70:656-65.

48. Kurmi O, Dunster C, Ayres J, Kelly F. Oxidative potential of smoke from burning wood and mixed biomass fuels. Free Radic Res. 2013;47(10):829-35.

49. Mudway IS, Duggan ST, Venkataraman C, Habib G, Kelly FJ, Grigg J. Combustion of dried animal dung as biofuel results in the generation of highly redox active fine particulates. Part Fibre Toxicol. 2005;2(1):6.

50. Keil C, Kassa H, Brown A, Kumie A, Tefera W. Inhalation exposures to particulate matter and carbon monoxide during Ethiopian coffee ceremonies in Addis Ababa: a pilot study. J Environ Public Health. 2010; 2010:213960.

51. Kumie A, Emmelin A, Wahlberg S, Berhane Y, Ali A, Mekonnen E, et al. Sources of variation for indoor nitrogen dioxide in rural residences of Ethiopia. Environ Health. 2009:8:51.
52. Zhuge Y, Qian H, Zheng X, Huang C, Zhang Y, Zhang M, et al. Residential risk factors for childhood pneumonia: a cross-sectional study in eight cities of China. Environ Int. 2018;116:83-91.

53. Hwang S-H, Hwang JH, Moon JS, Lee D-H. Environmental tobacco smoke and children's health. Korean J Pediatr. 2012;55(2):35.

54. Darrow LA, Klein M, Flanders WD, Mulholland JA, Tolbert PE, Strickland MJ. Air pollution and acute respiratory infections among children $0-4$ years of age: an 18-year time-series study. Am J Epidemiol. 2014;180(10):968-77.

\section{Publisher's Note}

Springer Nature remains neutral with regard to jurisdictional claims in published maps and institutional affiliations.
Ready to submit your research? Choose BMC and benefit from:

- fast, convenient online submission

- thorough peer review by experienced researchers in your field

- rapid publication on acceptance

- support for research data, including large and complex data types

- gold Open Access which fosters wider collaboration and increased citations

- maximum visibility for your research: over $100 \mathrm{M}$ website views per year

At BMC, research is always in progress.

Learn more biomedcentral.com/submissions 